\title{
Wildlife hunting by indigenous tribes: a case study from Arunachal Pradesh, north-east India
}

\author{
A mbika Aiyadurai, Navinder J. Singh and E. J. Milner-Gulland
}

\begin{abstract}
Hunting is a serious threat to wildlife worldwide. The rainforest-rich Arunachal Pradesh state of India, a biodiversity hotspot, is an area severely affected by indigenous hunting. The state has several indigenous tribes who hunt for food, trade, culture and leisure. Using semi-structured interviews and questionnaires we surveyed 184 individuals in 51 villages across four tribes for information on species hunted and hunting practices. A total of 33 mammalian species are reportedly hunted, of which only 11 were reported by hunters during formal interviews. The other 22 species were observed during casual visits, festivals and informal discussions. Of the species hunted 20 are Endangered, Vulnerable or Near Threatened on the IUCN Red List. Villagers now travel longer distances to hunt than they did a decade ago, suggesting a decline in wildlife populations around villages. The extent of offtake of mammals was related to the altitude of the village and the use of guns. Villagers living at higher altitudes and with guns appeared to hunt more. We also documented the importance of ritualistic hunting by some tribes. Additional research is required to estimate offtake and consumption rates of wild meat. Increasing conservation awareness and communitybased conservation projects may assist in controlling the severity and extent of this hunting problem.
\end{abstract}

Keywords Arunachal Pradesh, culture, Himalayas, hunting, indigenous, India, mammals, tribes

\section{Introduction}

T unting for, and trade in, animal parts is a major threat 1 to wildlife across the tropics (Bennett et al., 2002; Milner-Gulland et al., 2003). Local communities living in the vicinity of forests depend on native wildlife for food, trade, cultural purposes and income (Robinson \& Redford, 1991; Fa et al., 1995). With growing human populations, increased accessibility to remote forests and adoption of modern hunting methods and guns, the problem of hunting has become severe. In many places species are being extracted far above sustainable limits (Hill et al., 1997; Hart, 2002) because

\footnotetext{
Ambika Aiyadurai ${ }^{*}$ (Corresponding author), Navinder J. Singh and E. J. Milner-Gulland Department of Life Sciences, Imperial College London, Silwood Park, Ascot, Berkshire SL5 7PY, UK. E-mail ucsa014@ucl.ac.uk

${ }^{*}$ Current address: Department of Anthropology, University College London, Taviton Street, London, WC1H 0BW, UK

Received 14 March 2009. Revision requested 26 May 2009.

Accepted 13 August 2009.
}

of market demands for wild meat (Fa et al., 1995; Apaza et al., 2002). In areas where hunting is prevalent, wildlife populations have severely declined in biomass and there have been changes in the relative abundance of age classes (Peres, 2000). Control of this problem requires information on hunting patterns and understanding on the factors that drive local hunting (Bennett et al., 200o).

In Asia information on hunting is limited (Corlett, 2007) and largely restricted to trade (Banks et al., 2006), whereas in Africa and South America there are data on hunting for subsistence by indigenous communities (Robinson \& Redford, 1991). Even less is known about indigenous hunting in India, which contains two biodiversity hotspots and has dedicated environmental legislation (Anonymous, 1994). We focus our study on north-east India, a biodiversity hotspot where a strong cultural tradition of hunting exists. Although India has a tradition of wildlife protection (Rangarajan, 2001), indigenous communities in north-east India are culturally more similar to those in South-east Asia than those in peninsular India, and hence hunting practices are common (Datta, 2007). Hunting is cultural and widespread in the state of Arunachal Pradesh and has led to low wildlife abundance (Datta, 2002; Hilaluddin et al., 2005; Mishra et al., 2006).

To understand better the societal drivers of these hunting practices in Arunachal Pradesh, and the ecological impacts, baseline information on hunting is required. We designed this study to identify the drivers of hunting and generate baseline information on hunting trends in Arunachal Pradesh. We conducted surveys and semi-structured interviews to (1) document general hunting patterns across tribes (frequency of hunting, species hunted, reasons for hunting and not hunting, perceptions of hunting, techniques and taboos related to wildlife hunting), (2) identify the main factors determining hunting, and (3) identify the main predictors of level of offtake. We aimed to obtain a broad understanding of wildlife hunting based on a range of tribal cultural practices, geographical locations and hunting skills.

\section{Study area}

Arunachal Pradesh is in the Eastern Himalaya (Fig. 1), which is part of the Indo-Myanmar biodiversity hotspot (Myers et al., 2000) and one of the 200 globally important ecoregions (Olson \& Dinerstein, 1998). The state is also home to 26 indigenous communities, $80 \%$ of whom are primarily agriculturalists using shifting cultivation, and most land is community owned. These indigenous groups mostly have a cultural preference for wild meat (Hilaluddin 


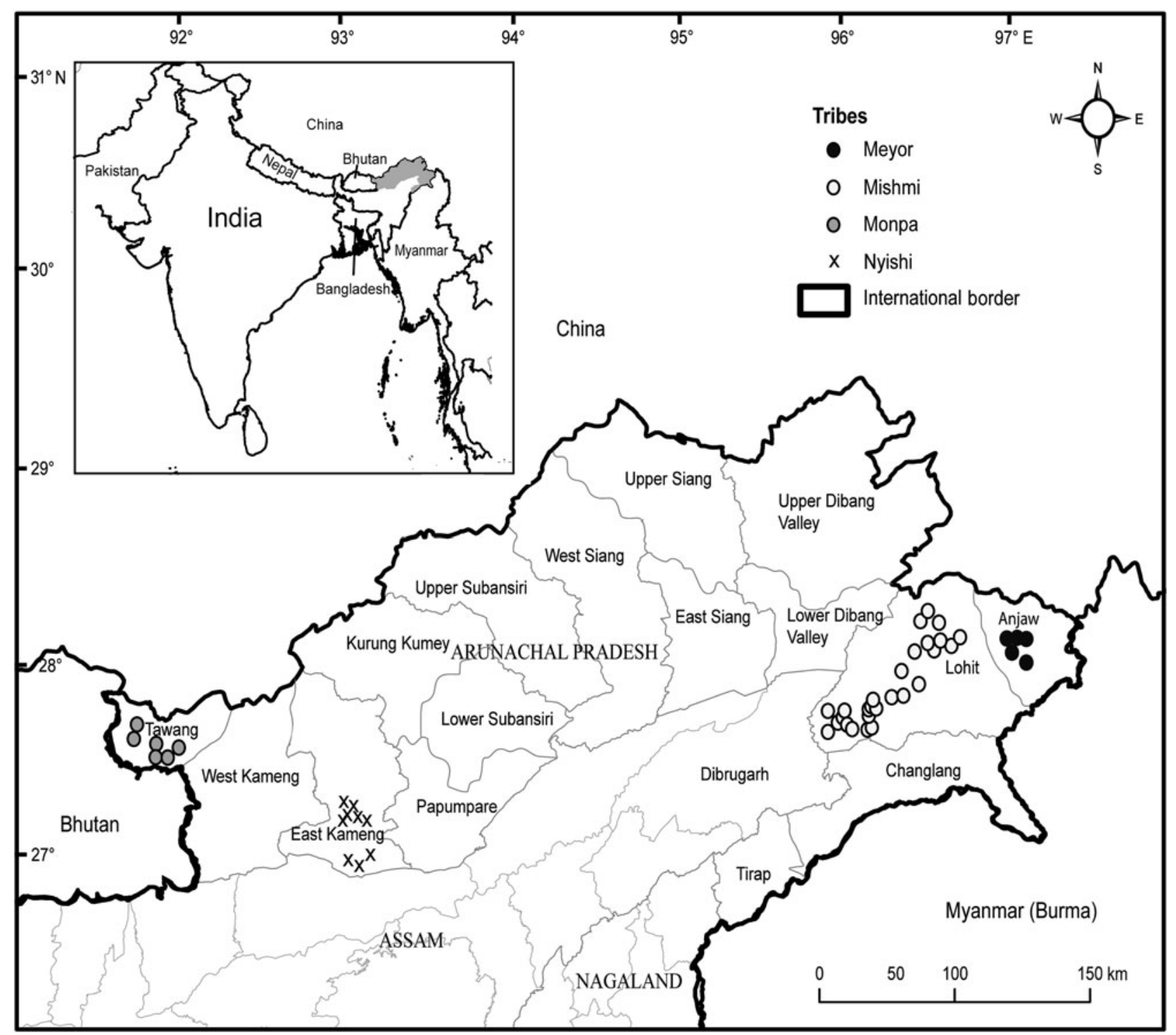

FIG. 1 The surveyed districts (Anjaw, Lohit, East Kameng and Tawang), villages and tribes in the state of Arunachal Pradesh in the eastern Himalaya, north-east India. The shaded area on the inset indicates the location of the main figure.

et al., 2005), which has an important role in their lives (Elwin, 1959; Fürer-Haimendorf, 1982, 1983). During 19912001 the human population in Arunachal Pradesh increased by $27 \%$, whereas the average increase for India was $21 \%$ (Anonymous, 2006), accompanied by changes from a subsistence to a cash economy.

Four main tribes, Nyishi, Mishmi (Miju and Digaru), Meyor and Monpa, inhabit the study region (Table 1). Most tribes in Arunachal Pradesh are site-specific. The study sites were chosen because they were the areas most accessible and feasible to study within the time and resources available.

\section{Methods}

An interview survey of 184 respondents, of four tribes, in 51 villages in four districts was carried out during January-
May 2006 (Table 1). We used semi-structured interviews, with questionnaires, with individual hunters. The variables considered were: species hunted, number of animals hunted in the previous hunting season (October-March), motivations for hunting, distances travelled to hunt now and in the past, whether hunting is a group or solitary activity, preferred season, time of hunting, duration, hunting success, and perceptions of wildlife abundance. Villages and households within each village were selected based on information from key informants (administrative officials, village headmen and school teachers). One male per household was interviewed (only men hunt). Women provided additional information related to consumption of meat. Interviews were conducted with the aid of field assistants who belonged to the tribe and spoke the local dialect. Most people agreed to be interviewed except in two 
TABLE 1 The number of villages, individuals surveyed, altitude range of surveyed villages, indigenous communities surveyed and belief systems in the four districts in Arunachal Pradesh (Fig. 1) in which we carried out surveys.

\begin{tabular}{llllll}
\hline & Villages & $\begin{array}{l}\text { Individuals } \\
\text { surveyed }\end{array}$ & $\begin{array}{l}\text { Altitude } \\
\text { range }(\mathrm{m})\end{array}$ & $\begin{array}{l}\text { Indigenous } \\
\text { communities }\end{array}$ & Belief system \\
\hline Anjaw & 13 & 34 & $700-1,640$ & Mishmi, Meyor & Animism, Buddhism \\
Lohit & 15 & 64 & $195-620$ & Mishmi & Animism \\
East Kameng & 14 & 51 & $165-1,000$ & Nyishi & Animism, Christianity \\
Tawang & 9 & 35 & $2,000-2,950$ & Monpa & Buddhism \\
\hline
\end{tabular}

households near the Kamlang Wildlife Sanctuary. Villagers were wary when notebooks were used while conducting interviews and therefore data were recorded, with permission, and transcribed later. Each interview lasted 30-40 minutes. Pictures were used to confirm the identity of particular species hunted.

We also witnessed religious ceremonies and traditional weddings in some of the villages to document the cultural value of wild and domestic animals. Hunters were asked to recall only mammals hunted. Villagers tend to remember mammals because they are large and of consumptive and economic value, and the number provided was thus more reliable than the number of birds or reptiles. A hunter's response for the previous season was also cross-checked with the number of skulls being smoked over fire in his house. Hunters often took pride in sharing information on hunting, which is part of their culture and an integral part of their lifestyle. Recent hunts (past 6-8 months) were identified from fresh animal remains and skulls and intact skins. Fresh skins are also dried in the sun and used as mats. If there was oil or fat under the skin, it also indicated a recent hunt. In some cases pheasant tail feathers were observed to have meat at their base, indicating fresh kills.

For assessing the frequency of hunting three categories were defined based on hunters' responses: very frequent trips (once per week), frequent trips (once per month) and rare trips (once in 3 months). Time spent on hunts was converted to three distance classes (half day to 1 day $=$ close to village, 2-3 days $=1-5 \mathrm{~km}$ from village and 1 week or more $\geq 5 \mathrm{~km}$ from village). The distance classes included both travel and hunting time. We asked the hunters how many attempts they were successful in every five hunts. Success was defined as hunted at least one mammal in the last five trips. The successes were converted to percentage categories: 0 times out of $5=0 \%, 1-2=30 \%, 3-4=70 \%$ and $5=100 \%$.

For Objective 1 (document general hunting patterns across the tribes), data from respondents who currently hunted were used (Nyishi, Meyor and Mishmi tribes). None of the Monpa admitted to hunting. Univariate analysis was used to determine correlations between variables. For Objective 2 (identify the main factors determining hunting) offtake in the previous season was the binomial response variable $(1=$ success in previous hunting season and $o=$ no success). For Objective 3 (determine predictors of level of offtake) the number of mammals killed by a hunter was the response variable. We validated data on species and numbers hunted, as provided by villagers, with animal remains (skulls and skins) that we observed. The explanatory variables were not related to a specific hunting trip but are general hunting attributes (Table 2).

The study has a hierarchical structure (one respondent per household per village per district) and therefore linear mixed effect (LME) models were used for analysis, with villages within district as random factors (Crawley, 2007). The minimum adequate model was selected based on stepwise deletion of variables that were not significant in the model, followed by analysis of variance to test the significance of the effect of the variable deletion. $R v$. 2.7.1 $(\mathrm{R}, 2008)$ was used for data analysis. The Meyor hunted frequently but because of the small sample size $(n=5)$ this tribe was not included in the main analysis. A small number of Nyishi families have adopted Christianity and therefore, as belief is confounded with tribe, only tribe was used in the analysis. Altitude of village and distance of village from town are confounded and therefore only altitude was used in the analysis because it was found to be a better predictor of offtake.

\section{Results}

Of the 184 interviewees 114 (62\%) stated that they currently hunt. The average age of hunters was significantly lower than that of non-hunters $(39.29 \pm \mathrm{SE} 0.99$ years, $\mathrm{n}=114$, vs $45.77 \pm$ SE 1.85 years, $\mathrm{n}=70, W=4957.5, \mathrm{P}=0.005, \mathrm{df}=1$ ). The average age of hunters did not differ between Mishmi, Meyor and Nyishi (Kruskal-Wallis test $\chi^{2}=4.57, \mathrm{df}=2$, $\mathrm{P}=0.20$ ).

\section{Reasons for hunting and not hunting}

Mishmi, Meyor and Nyishi reported food as the main reason for hunting, followed by money, rituals/customs, interest in hunting and retaliatory killing of crop-raiding animals (Fig. 2a). Cash income was an important reason for 
TAвLE 2 Details of explanatory variables for the linear mixed effect models of hunter success and mammal offtake in the previous season.

\begin{tabular}{|c|c|c|c|}
\hline Explanatory variables & Type & No. of categories & Categories/units \\
\hline Tribe & Categorical & 2 & Nyishi, Mishmi \\
\hline Distance travelled to hunt & Ordinal & 3 & Close to village, $1-5 \mathrm{~km},>5 \mathrm{~km}$ \\
\hline Frequency of hunting & Ordinal & 3 & $\begin{array}{l}\text { Very frequent (once per week), frequent } \\
\text { (once per month), rare (once per quarter) }\end{array}$ \\
\hline $\begin{array}{l}\text { Frequency of wild } \\
\text { meat consumption }\end{array}$ & Ordinal & 3 & $\begin{array}{l}\text { Once per week, at least once per month, } \\
\text { once per quarter }\end{array}$ \\
\hline Hunting group size & Binomial & 2 & $1, \geq 2$ \\
\hline Distance of village from town & Continuous & & $\mathrm{km}$ \\
\hline Altitude of village & Continuous & & $\mathrm{m}$ \\
\hline Age of hunter & Continuous & & Years \\
\hline Awareness of law & Binomial & 2 & Yes/no \\
\hline Use of a gun & Binomial & 2 & Yes/no \\
\hline Use of traps & Binomial & 2 & Yes/no \\
\hline Sale of wild meat \& products & Binomial & 2 & Yes/no \\
\hline
\end{tabular}

hunting by the Meyor. Mishmi (22\% of the responses) reported ritual as the main inspiration for hunting. Old age, religion, a hunting ban by the forest department and lack of interest in hunting were identified as primary reasons for
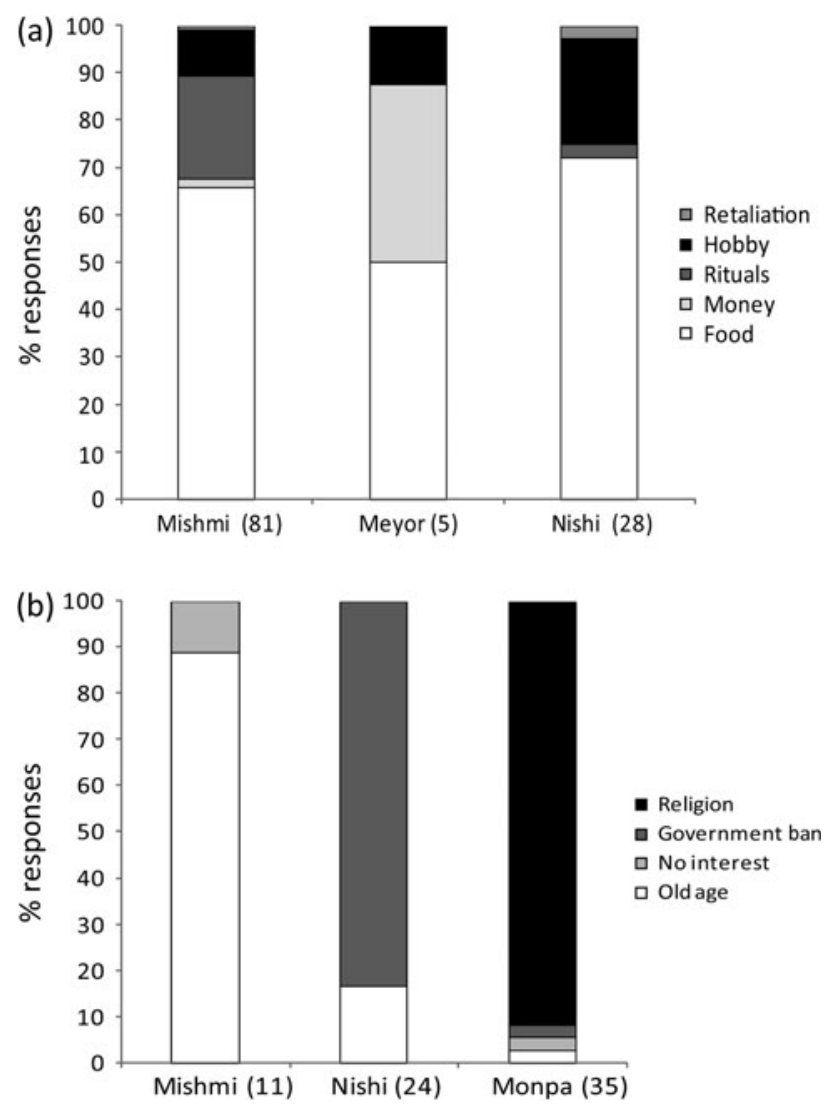

FIG. 2 Percentage responses indicating why individuals (a) hunt and (b) do not hunt, by tribe. Numbers in parentheses indicate number of respondents. Monpa are not included in (a) as they did not admit to hunting, and Meyor are not included in (b) because all Meyor respondents hunted. not hunting among the Mishmi, Nyishi and Monpa $(\mathrm{n}=$ 70; Fig. 2b). Religion accounted for $48 \%$ of the reasons (all respondents in this category were Monpa), followed by the forest department ban (31\%), old age (19\%) and lack of interest (3\%).

\section{Hunting attributes}

Hunters did not follow a fixed hunting schedule but hunted when convenient, although some hunting trips carried out for cultural or ritualistic reasons may follow a schedule, for example during village festivals and functions. During these periods hunting trips occur more often. Winter was the preferred hunting season for most hunters (93\%) and early in the morning the preferred time to hunt. The frequency of hunting by the three tribes was significantly different (Kruskal-Wallis test $\chi^{2}=7.2, \quad \mathrm{df}=2, \quad \mathrm{P}=0.03$ ), with Mishmi and Nyishi hunting more frequently compared to Meyor. There was a marked difference in the reported distances travelled between past and present hunting trips. Formerly, hunters rarely travelled $>5 \mathrm{~km}$ from their village, whereas 94 villagers said they currently travel distances of $>5 \mathrm{~km}$ to hunt. Distance categories in the past compared with the present were significantly different (Wilcoxon signed rank test, $W=600, \mathrm{P}<0.01, \mathrm{n}=109$ ). For all tribes the distance travelled was significantly shorter in the past than the present. The percentage categories of hunting successes by Mishmi and Nyishi is not significant (Wilcoxon signed rank test, $W=9, \mathrm{P}=0.25, \mathrm{df}=1$ ). Of the hunters interviewed $53 \%$ were $40-60$ years old, $43 \%$ 20-40, and six $>60$. People begin hunting from the age of 10-12 years and most continue hunting whilst their health permits. Boys $<20$ years old join the hunting groups as helpers, carrying loads and cooking. We often saw young boys using catapults for hunting birds and squirrels, and setting up small traps on the village farms for rodents and 
birds. We documented 11 trapping methods, including bows and arrows and spears but not blowguns. The indigenous methods documented were stone-fall, trigger-and-release, canopy, spring-pole, gum, metal noose, hanging stone, pitfall, box, log-fall and rodent traps.

\section{Species hunted}

A total of 33 species of mammals were hunted (Appendix), of which only 11 were reported by hunters during formal interviews (Table 3). The other 22 species were observed during casual visits, festivals and informal discussions. Of the species hunted 20 are categorized as Near Threatened, Endangered or Vulnerable (Appendix) on the IUCN Red List (2009). Skins of 29 mammal species, skulls of 11 and teeth of four were recorded in households, including both fresh remains and animals hunted less recently. Skulls of recently hunted animals are smoked on a bamboo tray above the fire. People use several articles, such as bags, skull caps and other headgear, made from animal parts. In addition, 27 species of birds and two reptiles were also reported, or observed, to be hunted.

\section{Determinants of hunting and offtake of mammals}

Average altitude of the hunters' villages was $719.34 \pm$ SE 86.5 $\mathrm{m}(\mathrm{n}=26$; range $227-1,641 \mathrm{~m})$, average offtake was $2 \pm \mathrm{SE}$ 0.5 mammals per hunter $(n=26)$, and the number of mammals hunted increased significantly with altitude (Spearman's test, $\mathrm{P}=0.05, \mathrm{df}=25$ ). Of 109 hunters (Nyishi and Mishmi) 47 had caught at least one mammal in the previous hunting season. None of the variables explained why people hunted but five variables (frequency of hunting, altitude of village, awareness of law, use of guns, use of traps) explained the number of mammals caught in the previous season (Table 4). Gun hunting and altitude of village were retained in the minimum adequate linear mixed effect model for the number of mammals reported hunted (Table 5). Hunters with guns reported hunting

TABle 3 Species hunted by villagers as indicated in interviews with three tribes (Mishmi, Nyishi and Meyor; $\mathrm{n}=114$ ).

\begin{tabular}{ll}
\hline Species & \% of responses \\
\hline Barking deer Muntiacus muntjak & 89 \\
Wild pig Sus scrofa & 85 \\
Asiatic black bear Ursus thibetanus & 36 \\
Sambar Cervus unicolor & 35 \\
Serow Nemorhaedus sumatraensis & 25 \\
Assamese macaque Macaca assamensis & 27 \\
Goral Nemorhaedus sp. & 27 \\
Capped langur Trachypithecus pileatus & 22 \\
Takin Budorcas taxicolor & 17 \\
Musk deer Moschus sp. & 11 \\
Malayan sun bear Helarctos malayanus & 7 \\
\hline
\end{tabular}

TABLE 4 Relationships between the number of animals caught in the past year by hunters (Mishmi and Nyishi only, $\mathrm{n}=109$ ) and potential explanatory variables (Table 2). The five significant relationships are in bold.

\begin{tabular}{|c|c|c|c|}
\hline Variables & Test & Test value & $\mathrm{P}$ \\
\hline Tribe & Wilcoxon & $W=201.5$ & 0.65 \\
\hline $\begin{array}{l}\text { Distance travelled } \\
\text { to hunt }\end{array}$ & Wilcoxon & $W=128$ & 0.70 \\
\hline Frequency of hunting & Kruskal-Wallis & $\chi^{2}=7.8, \mathrm{df}=2$ & 0.04 \\
\hline $\begin{array}{l}\text { Frequency of wild } \\
\text { meat consumption }\end{array}$ & Wilcoxon & $W=218$ & 0.40 \\
\hline Hunting group size & Wilcoxon & $W=224.5$ & 0.58 \\
\hline $\begin{array}{l}\text { Distance of village } \\
\text { from town }\end{array}$ & Spearman's & $S=15,441.97$ & 0.47 \\
\hline Altitude of village & Spearman's & $S=12,534.09$ & 0.05 \\
\hline Age of hunter & Spearman's & $S=17,789.20$ & 0.85 \\
\hline Awareness of law & Wilcoxon & $W=357$ & 0.05 \\
\hline Use of a gun & Wilcoxon & $W=221$ & 0.05 \\
\hline Use of traps & Wilcoxon & $W=297$ & 0.001 \\
\hline $\begin{array}{l}\text { Sale of wild meat \& } \\
\text { products }\end{array}$ & Wilcoxon & $W=175.5$ & 0.90 \\
\hline
\end{tabular}

significantly more mammals than those without guns ( $W=$ 221, $\mathrm{df}=1, \mathrm{P}=0.05)$.

\section{Cultural influences}

In interviews the Monpa denied hunting, citing religious reasons. During informal discussions with Monpa villagers in Tawang district, people reported retaliatory killing of wildlife to protect livestock and crops. Monpa villagers interviewed in the Pangchen Valley of Zemithang circle of Tawang district (Fig. 1) claimed that no one hunts in the valley because of strict religious taboos. Hunting for food is one of the main motivations for hunting in other tribes. The preference for wild meat was reportedly based on taste. People believed that wild meat is not contaminated like the meat of domestic animals that eat refuse around the villages. In the Mishmi tribe rituals also motivate hunting. Giving fresh or dried wild meat is a traditional practice during weddings, in which wild meat is given to the village priest and offered to guests. In one of the ceremonies attended a Temminck's tragopan Tragopan temminckii, trapped alive, was given to the priest. Use of wild meat in rituals was important irrespective of the species. Domestic

TABLE 5 Minimum adequate linear mixed effect model for the number of mammals reported to have been killed in the previous year. The model has villages in district as a random effect $(86 \%$ of the variation) and a Gaussian error structure, and was fitted by maximum likelihood.

\begin{tabular}{lclllr}
\hline & Estimate & SE & df & $t$ & \multicolumn{1}{c}{ P } \\
\hline Intercept & -0.510 & 0.620 & 22 & -0.822 & 0.419 \\
Altitude & 0.002 & 0.000 & 22 & 4.04 & $<0.001$ \\
Use of a gun & 1.566 & 0.511 & 18 & 3.060 & 0.006 \\
\hline
\end{tabular}


animals are viewed as a reserve that is also needed for sacrifice during rituals. Because of inadequate healthcare facilities in these remote areas, villagers often rely on local village priests and healers who recommend the use of domestic meat for curing illnesses. There is conversion of local tribes to Christianity, which appears to affect hunting traditions in terms of practices followed. In addition, conversion to Christianity also probably leads to an erosion of hunting taboos. For instance, those who have converted stop displaying animal skulls in their huts but continue to hunt. A stuffed red panda Ailurus fulgens, trophies of sambar Rusa unicolor, skins of barking deer Muntiacus muntjak and Chinese pangolin Manis crassicaudata are some of the wildlife parts that we found in government staff quarters that had been received as gifts or occasionally bartered for by Army personnel.

Cash income was an important reason for hunting by the Meyor. Certain species that have valuable commercial parts, such as otter Aonyx sp., musk deer Moschus sp. and Asiatic black bear Ursus thibetanus are hunted primarily for sale. Hunters reported that musk pod, bear gall bladder and other animal skins are sold in towns in the neighbouring state of Assam. Villagers in Anjaw and Lohit districts often sell the animal parts to shopkeepers (not from Arunachal Pradesh) who then sell them in towns outside the state. Special trips to hunt takin Budorcas taxicolor and musk deer are made during August-September, when hunters are free from agricultural work because the harvest season has finished.

\section{Discussion}

This study provides new information on hunting practices and species harvested and the socio-economic factors affecting the exploitation of wildlife in Arunachal Pradesh, and also highlights the cultural use of wildlife by the state's indigenous groups. Offtake levels are higher in highaltitude villages, which are also the most remote. However, it is hard to assign causation to this observation without further information. This higher offtake could be because more wildlife is present or because of greater hunter effort. The fact that the use of a gun is an important predictor of higher offtake suggests that the replacement of traditional hunting methods with advanced weapons is important in improving hunter yields. This could lead to local extinction of some species, especially in remote regions where law enforcement is weak and long-term hunting has already reduced wildlife populations. The increased distances now travelled to hunt compared to formerly indicate a possible decline in wildlife populations around villages. In addition to guns villagers also use traditional trapping methods. Trapping requires more time and traditional knowledge of the area, which may limit its impact compared to guns.

Our findings are a first step in understanding hunting practices in this understudied region. However, the re- search was logistically constrained. Our reliance on hunter recall is a limitation, although it is sometimes the only available approach to obtain data on harvest levels among indigenous communities (Usher \& Wenzel, 1987). However, confidence in this method is improved if other data can be used for validation. We found that recall was not reliable; an examination of animal remains substantially increased the list of species hunted. Recording fresh remains therefore provided supplementary evidence of offtake that we could use to triangulate and supplement the recall data. We used the recall period of the previous hunting season and focused on mammals; this was appropriate because a hunt for a mammal species is a momentous and infrequent event, which villagers could remember and categorize into economic, cultural and consumptive purposes. We did not ask about hunting of other taxonomic groups, such as birds and fish, where the recall was less likely to be reliable and remains were also less likely to be displayed. Jones et al. (2008) demonstrated that 1-year recall of harvesting behaviour can be reliable in certain circumstances. Thus, despite some of the limitations of our study the information obtained is novel and may be valuable for future studies in the region.

There was little wariness amongst respondents in answering questions about hunting. Only in a few villages close to town were people not prepared to discuss their hunting practices with us. The level of awareness about hunting laws is generally low in the region except near wildlife reserves (Pakke Tiger Reserve in East Kameng, Kamlang Wildlife Sanctuary in Lohit) and in Tawang. Another study that documented hunting in Tawang reported that hunting may have declined following the visit of the Dalai Lama, the spiritual leader of Buddhism, in 2003 (Mishra et al., 2006).

Hunting is part of the culture of many indigenous communities and the multidimensional nature of hunting motivations makes studying the drivers of hunting behaviour particularly difficult (Caldecott, 1988; Robinson \& Bennett, 2000; Silvius et al., 2004; Rao et al., 2005). Our study revealed various motivations for hunting but ultimately the animal hunted ended up in the pot or in the market. The presence of alternate sources of protein from domestic meat (cows, chicken and pigs) in every household and respondents' livelihoods as swidden farmers or cash croppers suggest that wildlife is not an essential component of their diet. In this region hunting seems to be more important as a cultural practice than as a livelihood but wild meat is preferred over domestic meat. Ritualistic hunting appears to be an important component of the culture of the Mishmi and Nyishi. Giving gifts of fresh or dried wild meat is a traditional practice at Mishmi weddings and village festivals, and the number of baskets of wild meat given as the bride price represents the status of the bridegroom. Nyishi men wear a hornbill beak as part of their traditional head gear. 
We do not attempt to draw conclusions from this study about the sustainability of hunting in the region. More intensive and focused research is required to quantify hunting and evaluate the outcomes of a range of potential conservation interventions. Our results suggest that offtake of wild mammals is low, with only a few animals hunted each year in a given village. However, in the absence of more detailed information on the abundance and distribution of the hunted species, this low offtake cannot be taken as implying either that hunting is not affecting wildlife populations or that wildlife is severely depleted. Hunting and trading of rare and threatened species such as clouded leopard Neofelis nebulosa, musk deer, Asiatic black bear and takin is a matter of concern as it is likely to have an impact even at low levels of offtake. Our study also suggests that the areas around villages may already be depleted, with hunters now having to travel further afield. Hunting with guns probably started a century ago (Bailey, 1912) and its impact, coupled with increasing accessibility by road, may have led to the depletion of wildlife around villages. This could lead to empty forests, especially in remote regions with low levels of law enforcement and where local people have traditionally hunted (Datta et al., 2008).

The state of Arunachal Pradesh is undergoing rapid changes, with development projects such as hydroelectric dams, road construction and establishment of commercial markets. Migration from other states has led to a four-fold growth in the human population since 1947 (Anonymous, 2006). This increasing population may lead to increased offtake if hunting continues at a constant low rate per capita. In other areas population increases and rapid changes in socio-economic circumstances of indigenous communities have caused similar concerns about wildlife populations (Rao et al., 2005; Golden, 2009; Zapata-Ríos et al., 2009). Such developments also threaten local culture and may thus change villagers' relationships with wildlife and nature. For example, a shift towards Christianity in our study area could lead to more hunting of species that were previously protected by hunting taboos. Any moves to reduce offtake will require careful planning as hunting in this region is not just an economic activity but is linked to the cultural practices of local communities. More in-depth studies, combining ecological and cultural knowledge, are required for a better understanding of the drivers of hunting in this region.

\section{Acknowledgements}

Financial support was provided by the Rufford Small Grants Foundation, UK, and a Research Fellowship Programme grant from the Wildlife Conservation Society, USA. NS was funded by the Leverhulme Trust, UK. We thank the Nature Conservation Foundation for providing support during the survey, Drs Aparajita Datta and M.D.
Madhusudan of the Nature Conservation Foundation for guidance, Arunachal Pradesh Forest Department, especially Pekyom Ringu, for permissions to carry out this work, and Dr Sarit Chowdhury (Rajiv Gandhi University, Itanagar), Milo Kojin, Perme, Bida, Tana Tapi, Khandu, and Col Yadav, Lt Col Sharma and Maj Gurung of the Indian Army for their help and cooperation in Anjaw, East Kameng, Tawang and Lohit districts, our assistants Lobinso Malo, Sataw Ama, Gombu Meyor, Sonam Chotan, Kumar, Rasham, Om and Dorje for valuable field support, the villagers for providing assistance and hospitality and for sharing information, Raghunath (NCF) and Satish Kumar for help in map preparation and the Ford Foundation's International Fellowship Programme for funding AA's study at Imperial College London.

\section{References}

Anonymous (1994) The Indian Wildlife Protection Act, 1972 (as Amended up to 1993). Natraj Publishers, Dehra Dun, India. Anonymous (2006) Arunachal Pradesh Human Development Report 2005. Government of Arunachal Pradesh, Itanagar, India.

Apaza, L., Wilkie, D., Bryon, E., Haunch, T., Leonard, W., Perez, E. et al. (2002) Meat prices influence the consumption of wildlife by the Tisane Amerindians of Bolivia. Oryx, 36, 382-388.

B ailey, F.M. (1912) Report on the Work of the Dibang ColumnMishmi Mission (1911-1912). IOR/MSS/EUR F 157, 304 (d).

Banks, D., Desai, N., Gosling, J., Joseph, T., Majumdar, O., Mole, N. et al. (2006) Skinning the Cat: Crime and Politics in the Big Cat Skin Trade. Environmental Investigation Agency and Wildlife Protection Society of India, London, UK.

Bennett, E.L., Milner-Gulland, E.J., Bakarr, M., Eves, H.E., Robinson, J.G. \& Wilkie, S.D. (2002) Hunting the world's wildlife to extinction. Oryx, 36, 328-329.

Bennett, E.L., Nyaoi, A.J. \& Sompud, J. (2000) Saving Borneo's bacon: the sustainability of hunting in Sarawak and Sabah. In Hunting for Sustainability in Tropical Forests (eds J.G. Robinson \& E.L. Bennett), pp. 305-324. Columbia University Press, New York, USA.

Caldecott, J. (1988) Hunting and Wildife Management in Sarawak. IUCN, Gland, Switzerland.

Corlett, R.T. (2007) The impact of hunting on the mammalian fauna of tropical Asian forests. Biotropica, 39, 292-303.

Crawley, M.J. (2007) The R Book. John Wiley, Chichester, UK.

D A T T A, A. (2002) Status of Hornbills and Hunting among Indigenous Communities in Eastern Arunachal Pradesh. Unpublished Report. Wildlife Conservation Society and WCS-India Programme, Bangalore, India.

Datta, A. (2007) Protecting with people in Namdapha: threatened forests, forgotten people. In Making Conservation Work: Securing Biodiversity in This New Century (eds G. Shahabuddin \& M. Rangarajan), pp. 165-209. Permanent Black, New Delhi, India.

Datta, A., Anand, M.O. \& Naniwadekar, R. (2008) Empty forests: large carnivore and prey abundance in Namdapha National Park, north-east India. Biological Conservation, 141, 1429-1435.

Elwin, V. (1959) A Philosophy for NEFA (1999 reprint). Directorate of Research, Government of Arunachal Pradesh, Itanagar, India.

Fa, J.E., Juste, J., Delval, J.P. \& Castroviejo, J. (1995) Impact of market hunting on mammal species in Equatorial Guinea. Conservation Biology, 9, 1107-1115. 
Fürer-Haimendorf, C. von. (1982) Highlanders of Arunachal Pradesh: Anthropological Research in North-east India. Garlandfold in association with Vikas, London, UK.

Fürer-Haimendorf, C. von (1983) Himalayan Adventure, Early Travels in North-East India. Sterling Publishers, New Delhi, India.

Golden, C.D. (2009) Bushmeat hunting and use in the Makira Forest, north-eastern Madagascar: a conservation and livelihoods issue. Oryx, 43, 386-392.

H A R , J.A. (2002) Impact and sustainability of indigenous hunting in the Ituri Forest, Congo-Zaire: a comparison of unhunted and hunted duiker populations. In Hunting for Sustainability in Tropical Forests (eds J.G. Robinson \& E.L. Bennett), pp. 106-153. Columbia University Press, New York, USA.

Hilaluddin, Kaul, R. \& Ghose, D. (2005) Conservation implications of wild animal biomass extractions in North-east India. Animal Biodiversity and Conservation, 28, 169-179.

Hill, K., Padwe, J., Bejyvagi, C., Bepurangi, A., Jakugi, F., Tykuarangi, R. \& Tykuranngi, T. (1997) Impact of hunting on large vertebrates in the Mbaracayu Reserve, Paraguay. Conservation Biology, 6, 1339-1353.

IUCN (2009) IUCN Red List of Threatened Species v. 2009.1. Http:// www.iucnredlist.org [accessed 22 January 2010].

Jones, J.P.G., Andriamarovololona, M.A., Hockley, N., Gibbons, J.M. \& Milner-Gulland, E.J. (2008) Testing the use of interview as a tool for monitoring trends in the harvesting of wild species. Journal of Applied Ecology, 45, 1205-1212.

Milner-Gulland, E.J., Bennett, E.L. \& the SCB 2002 Annual Meeting Wild Meat Group (2003) Wild meat: the bigger picture. Trends in Ecology \& Evolution, 18, 351-357.

Mishra, C., Madhusudan, M.D. \& Datta, A. (2006) Mammals of the high altitudes of western Arunachal Pradesh, eastern Himalaya: an assessment of threats and conservation needs. Oryx, 40, 29-35.

Myers, N., Mittermeier, R.A., Mittermeier, C.A., da Fonseca, G.A.B. \& KeNT, J. (2000) Biodiversity hotspots for conservation priorities. Nature, 403, 853-858.

Olson, D.M. \& Dinerstein, E. (1998) The global 200: a representation approach to conserving the earth's most biologically valuable ecoregions. Conservation Biology, 12, 502-515.
Peres, C.A. (2000) Evaluating the impact and sustainability of subsistence hunting at multiple Amazonian forest sites. In Hunting for Sustainability in Tropical Forests (eds J.G. Robinson \& E.L. Bennett), pp. 31-56. Columbia University Press, New York, USA.

R (2008) The R Project for Statistical Computing. Http://www.rproject.org/ [accessed 16 April 2010].

Rangarajan, M. (2001) India's Wildlife History: An Introduction. Permanent Black, New Delhi, India.

Rao, M., Myint, T., Zaw, T. \& Htun, S. (2005) Hunting patterns in tropical forests adjoining the Hkakaborazi National Park, north Myanmar. Oryx, 39, 292-300.

Robinson, J.G. \& BennetT, E.L. (eds) (2000) Hunting for Sustainability in Tropical Forests. Columbia University Press, New York, USA.

Robinson, J.G. \& Redford, K.H. (eds) (1991) Neotropical Wildlife Use and Conservation. University of Chicago Press, Chicago, USA.

Silvius, K.M., Bodmer, R.E. \& Jose, F. (2004) People in Nature. Columbia University Press, New York, USA.

Usher, P.J. \& W ENZEL, G. (1987) Native harvest surveys and statistics: a critique of their construction and use. Arctic, 40, 145-160.

Zapata-Ríos, G., Urgilés, C. \& SuÁrez, E. (2009) Mammal hunting by the Shuar of the Ecuadorian Amazon: is it sustainable? Oryx, 43, 375-385.

\section{Biographical sketches}

Ambika Aiyadurai's main interests are in studying wildlife hunting practices in Arunachal Pradesh and understanding indigenous hunting from both ecological and anthropological perspectives. NAVINDER J. SingH is interested in monitoring of biodiversity as a conservation tool and understanding population dynamics of threatened species in stochastic environments. E. J. MiLnER-GULLAND studies population dynamics of exploited species and the incentives of the people who hunt them.

Appendix Mammals hunted by indigenous tribes in four districts in Arunachal Pradesh (Fig. 1), with their IUCN Red List (IUCN, 2009) category, and whether skin/scales, skulls or teeth were recorded in households during interviews.

\begin{tabular}{|c|c|c|c|c|}
\hline Species & Red List category* & Skin/scales & Skull & Teeth \\
\hline Southern red muntjac Muntiacus muntjak & LC & $\sqrt{ }$ & $\sqrt{ }$ & \\
\hline Musk deer Moschus leucogaster & EN & $\sqrt{ }$ & & \\
\hline Sambar Rusa unicolor & VU & & $\sqrt{ }$ & \\
\hline Indian bison Bos gaurus & VU & & $\sqrt{ }$ & \\
\hline Himalayan serow Capricornis thar & NT & $\sqrt{ }$ & $\sqrt{ }$ & \\
\hline Takin Budorcas taxicolor & VU & $\sqrt{ }$ & $\sqrt{ }$ & \\
\hline Himalayan goral Naemorhedus goral & NT & $\sqrt{ }$ & $\sqrt{ }$ & \\
\hline Eurasian wild pig Sus scrofa & $\mathrm{LC}$ & & $\sqrt{ }$ & \\
\hline Himalayan black bear Ursus thibetanus & VU & $\sqrt{ }$ & $\sqrt{ }$ & $\sqrt{ }$ \\
\hline Malayan sun bear Helarctos malayanus & VU & $\sqrt{ }$ & & \\
\hline Red panda Ailurus fulgens & VU & $\sqrt{ }$ & & \\
\hline Tiger Panthera tigris & EN & $\sqrt{ }$ & $\sqrt{ }$ & $\sqrt{ }$ \\
\hline Leopard Panthera pardus & NT & $\sqrt{ }$ & $\sqrt{ }$ & \\
\hline Clouded leopard Neofelis nebulosa & $\mathrm{VU}$ & $\sqrt{ }$ & & $\sqrt{ }$ \\
\hline Asiatic golden cat Pardofelis temminckii & NT & $\sqrt{ }$ & & \\
\hline Leopard cat Prionailurus bengalensis & LC & $\sqrt{ }$ & & \\
\hline
\end{tabular}


ApPEndix (Continued)

\begin{tabular}{|c|c|c|c|c|}
\hline Species & Red List category* & Skin/scales & Skull & Teeth \\
\hline Chinese pangolin Manis pentadactyla & $\mathrm{EN}$ & $\sqrt{ }$ & & \\
\hline Yellow-throated marten Martes flavigula & $\mathrm{LC}$ & $\sqrt{ }$ & & \\
\hline Spotted linsang Prionodon pardicolor & LC & $\sqrt{ }$ & & \\
\hline Dhole Cuon alpinus & $\mathrm{EN}$ & $\sqrt{ }$ & & \\
\hline Golden jackal Canis aureus & $\mathrm{LC}$ & $\sqrt{ }$ & & \\
\hline Assam macaque Macaca assamensis & NT & $\sqrt{ }$ & $\sqrt{ }$ & \\
\hline Capped langur Trachypithecus pileatus & VU & $\sqrt{ }$ & & \\
\hline Orange-bellied Himalayan squirrel Dremomys lokriah & $\mathrm{LC}$ & $\sqrt{ }$ & & \\
\hline Flying squirrel species & & $\sqrt{ }$ & & \\
\hline Black giant squirrel Ratufa bicolor & NT & $\sqrt{ }$ & & \\
\hline Large Indian civet Viverra zibetha & NT & $\sqrt{ }$ & & \\
\hline Common palm civet Paradoxurus hermaphroditus & $\mathrm{LC}$ & $\sqrt{ }$ & & \\
\hline Masked palm civet Paguma larvata & LC & $\sqrt{ }$ & & \\
\hline Malayan crestless porcupine Hystrix brachyuran & LC & $\sqrt{ }$ & & \\
\hline
\end{tabular}

${ }^{\star}$ LC, Least Concern; NT, Near Threatened; VU, Vulnerable; EN, Endangered. Note that Least Concern indicates the species has been assessed and found not to be Near Threatened or in one of the three threatened categories. 